\title{
Introgression of crown rust (Puccinia coronata) resistance from meadow fescue (Festuca pratensis) into Italian ryegrass (Lolium multiflorum) and physical mapping of the locus
}

\author{
HW Roderick, WG Morgan, JA Harper and HM Thomas \\ Institute of Grassland and Environmental Research, Plas Gogerddan, Aberystwyth SY23 3EB, UK
}

Resistance was found in the meadow fescue (Festuca
pratensis) to crown rust (Puccinia coronata), originating from
ryegrasses (Lolium spp). A backcrossing programme suc-
cessfully transferred this resistance into diploid Italian
ryegrass (Lolium multiflorum) and genomic in situ hybridisa-
tion (GISH) was used to identify the introgressed fescue
chromosome segment. The resistant $(\mathrm{R})$ plants in two $\mathrm{BC}_{3}$
lines all carried an introgressed segment on a single
chromosome, which in one of the lines was confined to the
short arm of the chromosome. Susceptible (S) plants either

Keywords: Lolium multiflorum; Puccinia coronata; Festuca pratensis; crown rust resistance; introgression

contained no introgressed chromosome segment or a segment which was physically smaller than the segments in resistant plants. Using GISH the resistance locus could be physically mapped to the midpoint of a short arm. Segregation ratios of the progeny of $\mathrm{BC}_{3}$ plants, when crossed as $R \times S$ and $R \times R$, were in agreement with the hypothesis that the resistance was controlled by a single gene or very closely linked genes. No R plants were produced by crossing $\mathrm{S} \times \mathrm{S}$ plants.

Heredity (2003) 91, 396-400. doi:10.1038/sj.hdy.6800344

\section{Introduction}

Crown rust (Puccinia coronata) is a common disease of ryegrasses, and is probably the most serious fungal disease of perennial ryegrass (Lolium perenne) in the UK and western Europe (Potter et al, 1990). It is apparently becoming more widespread in Europe, and while it is normally most prevalent in late summer and autumn, there are many recent reports of the disease appearing earlier (Reheul et al, 2001). It is found in almost every region of the world where perennial ryegrass is grown (Kimbeng, 1999). Many grasses are hosts to crown rust including other agriculturally important species such as meadow fescue (Festuca pratensis), as well as other Festuca spp (Braverman, 1967, 1986). The fungus exists in different physiological forms and this manifests itself both at the formae speciales level - its capacity to infect certain grass species - and as physiological races - specificity to certain genotypes within the species. However, the relationship between different hosts and physiological forms of the fungus is complex (Dinoor et al, 1988). Therefore, within any host species some susceptibility to $P$. coronata from an unrelated species can occur especially under artificial conditions in a glasshouse or growth cabinet. Consequently, within a population of $F$. pratensis, individual plants can differ in their reaction to infection by

Correspondence: HW Roderick, Institute of Grassland and Environmental Research, Plas Gogerddan, Aberystwyth SY23 3EB, UK.

E-mail: hywel.roderick@bbsrc.ac.uk

Received: 25 April 2003
P. coronata originating from Lolium spp, with some populations having a relatively high proportion of susceptible plants (personal observation). Thus, F. pratensis should perhaps be considered as another potential source of resistance parallel to the ones derived from Lolium spp rather than as a 'nonhost'.

Meadow fescue (F. pratensis) and the two cultivated ryegrass species, Italian ryegrass (L. multiflorum) and perennial ryegrass (L. perenne), are closely related with a degree of homology between their chromosomes (Jauhar, 1975). On the other hand, the relationship is sufficiently distant that L. multiflorum $(\mathrm{Lm})$ and F. pratensis $(F p)$ chromosomes can be distinguished in hybrid plants using genomic in situ hybridisation (GISH) (Thomas et al, 1994). The potential use of Lolium/Festuca introgression mapping to develop physical and genetic maps, determine the genetic control of important characters and develop new germplasm for plant breeders has been discussed previously (King et al, 1998). Using this technique, it has been possible to identify a segment of chromosome from $F$. arundinacea introgressed into $\mathrm{Lm}$ and carrying drought tolerance (Humphreys and Pasakinskiene, 1996). It should be possible to identify the region of the $\mathrm{Fp}$ chromosome carrying genes for other traits, such as disease resistance. Wilkins et al (1974) showed that an amphiploid between $L m$ and F. arundinacea exhibited the resistance characteristics of both its parents to the corresponding 'nonhost' strain of $P$. coronata. Oertel and Matzk (1999) obtained introgression of crown rust resistance from both $F p$ and $F$. arundinacea into $\mathrm{Lm}$. The segregation ratios in the 
progeny of intercrosses of resistant and susceptible $\mathrm{BC}_{3}$ plants and selfed $\mathrm{R}$ plants suggested that the resistance was controlled by two or more dominant genes which were linked in most cases. A possible advantage of using resistance derived from Festuca spp is that it might be more stable at high temperature and therefore more effective in warmer regions (Roderick et al, 2000).

In this paper we report on the development of introgressed lines between crown rust-susceptible $\mathrm{Lm}$ and resistant $F p$ and on the use of chromosome painting to identify the region of chromosome carrying resistance.

\section{Materials and methods}

Inoculation procedure and selection of parents

Freshly collected uredospores of an UK isolate of crown rust $(P$. coronata) were collected from infected plants of $L$. perenne and $L m$. For plant inoculations, the spores were diluted in odourless kerosene (Barretine Ltd, UK) at a concentration of $20 \mathrm{mg} / \mathrm{ml}$ and sprayed over the host material using a hand-held atomiser (Humbrol Ltd, UK). The plants were either incubated in a dew simulation chamber at $20^{\circ} \mathrm{C}$ (Clifford, 1973) or, for more plants, in a $20^{\circ} \mathrm{C}$ growth chamber fitted with a humidifier which atomised a fine mist of tap water over the plants at intervals of $20 \mathrm{~h}$ in the dark. The plants were then transferred to growth chambers at a continuous temperature of $25^{\circ} \mathrm{C}$ and a $12 \mathrm{~h} / 12 \mathrm{~h}$ dark/light period and light intensity of $200 \mathrm{mE} \mathrm{m}^{2} \mathrm{~s}^{2}$. Rust pustules erupted after 9 days on susceptible plants and the expression of resistance was assessed at least twice, after 10 and 14 days. If there was no visible sign of infection (immune) or small chlorotic spots, plants were designated as resistant. Intermediate types had some small pustules along with chlorotic spots, whereas susceptible plants had medium to large pustules. No attempt was made to quantify the amount of infection. Since the $F_{1}$ plants had twice as many chromosomes originating from $L m$ as $F p$ (see below), it was considered possible that resistance would not have been fully expressed in the $F_{1}$, and therefore no selection was made at this stage. The most resistant plants were selected for further crossing from the $\mathrm{BC}_{1}$ generation onwards.

\section{Parental material}

Five populations of $F p$ from diverse origins were initially screened for resistance to crown rust and two populations contained plants that were resistant. The backcross lines that were eventually selected originated from an ecotype collected in natural grazing pasture at $360 \mathrm{~m}$ above sea level in the Moldavia region of Romania (IGER accession Bf 1204), on which there was no apparent host response to infection and was classified as immune. The other, IGER accession Bf 993, was a line bred for a slow senescence character. Susceptible $\mathrm{Lm}$ parents were obtained from cultivars known to be relatively susceptible to crown rust.

An example of the crossing procedure used to obtain crown rust-resistant $\mathrm{BC}_{3}$ lines is shown in Figure 1. In this case, triploid $F_{1}$ hybrids were produced using a crown rust-susceptible tetraploid genotype of $\mathrm{Lm}$ $(2 n=4 x=28)$ as the female parent, and a resistant $F p$ as the pollen donor. Tetraploid $L m$ was used as this has been proven to be the most efficient route to obtain

$$
\begin{aligned}
& \text { q } \hat{0} \\
& \text { L. multiflorum }(4 \mathrm{x}=28) \times F \text {. pratensis }(2 \mathrm{x}=14) \\
& \text { cv. Celebrity Bf } 1204 \\
& \text { Crown rust (CR) susceptible CR resistant } \\
& \mathrm{F}_{1}(2 \mathrm{n}=3 \mathrm{x}=21) \times \text { L. multiflorum }(2 \mathrm{x}) \\
& \text { cv. Abercomo } \\
& \text { CR resistant CR susceptible } \\
& \text { L. multiflorum }(2 \mathrm{x}) \times \mathrm{Bc}_{1}(1 / 3 / 6)(2 \mathrm{n}=15) \\
& \text { cv. Trajan } \\
& \text { CR susceptible CR resistant } \\
& \text { L. multiflorum }(2 \mathrm{x}) \times \overrightarrow{\mathrm{Bc}}_{2}(2 / 2 / 3)(2 \mathrm{n}=14) \\
& \text { cv. Meribel } \\
& \text { CR susceptible CR resistant } \\
& \mathrm{Bc}_{3}(3 / 2)(2 \mathrm{n}=14) \\
& \text { CR resistant }
\end{aligned}
$$

Figure 1 Crossing procedure used to obtain crown rust-resistant introgression line $3 / 2$ between L. multiflorum and F. pratensis.

introgression (King et al, 1998; Thomas et al, 1988). For the first backcross generation, the triploid $F_{1}$ hybrids $(2 n=3 x=21)$ were used as both the male and female parent, since some were male sterile or had low male fertility. Susceptible $L m$ genotypes of cV. Abercomo $(2 n=2 x=14)$ were selected as the other parent. In the subsequent generations, resistant BC plants were used as the male parent and crossed with a diploid $L m$ genotype.

\section{Cytological assessment and in situ hybridisation}

Mitotically dividing root cells of selected crown rustresistant progeny were assessed for their chromosome complement in all generations. Roots were produced from detached vegetative tillers on an aerated culture tank (Morgan, 1976). Excised root tips were kept in icecold water either for $16 \mathrm{~h}$ (for mitotic cell divisions) or $18 \mathrm{~h}$ (for in situ hybridisation) and then fixed in ethanol:acetic acid $(3: 1)$ for a minimum of $2 \mathrm{~h}$. For chromosome counts, root tips were stained by the Feulgen method and squashed on a microscope slide in $1 \%$ acetocarmine. For in situ hybridisation, metaphase spreads were treated by the procedure described by Thomas et al (1994) and King et al (1998). Total genomic $F p$ DNA was used as a probe to detect $F p$ introgressions; this was labelled either with Cy3-dCTP (Amersham Pharmacia Biotech, UK) (red) or dig-11-dUTP (Boehringer Mannheim, UK) and detected by the fluorescein detection procedure (green). The Fp DNA was combined with unlabelled Lolium DNA in the ratio 1:40. The clone pTa71, which contains the 18S-5.8S-26S rDNA gene cluster, was labelled with dig-11-dUTP and incorporated into the hybridisation mixture to help identify individual chromosomes (Thomas et al, 1997); this hybridises to the Lolium and Festuca rDNA sites. Slides were examined using a Leica DM/RB epifluorescence microscope with filters for DAPI, fluorescein and rhodamine. Images were captured with a Nikon FDX-35 camera on Fujichrome 400 colour slide film or captured directly using a Coolview CCD monochrome camera (Thomas et al, 1996). The $35 \mathrm{~mm}$ images were subsequently scanned into Adobe Photoshop for digital reproduction. 


\section{Results}

Both resistant $(\mathrm{R})$ and susceptible $(\mathrm{S})$ triploid $\mathrm{F}_{1}$ plants were identified. In seven cases, sufficient $\mathrm{BC}_{1}$ progenies were obtained for crown rust testing. Three of these lines, all originating from resistant $\mathrm{F}_{1}$ plants, were segregating for resistance (Table 1 ). In the remaining $\mathrm{BC}_{1}$ lines, originating from susceptible $\mathrm{F}_{1}$ plants, only one resistant plant and 13 intermediate types were found.

In two $\mathrm{BC}_{2}$ lines, obtained by crossing crown rustresistant plants of $\mathrm{BC}_{1}$ line $1 / 3$ with a susceptible diploid $\mathrm{Lm}$ plant, clearly different segregation ratios were recorded. The ratio of $\mathrm{R}: S$ plants in $\mathrm{BC}_{2}$ line $2 / 1$ was significantly different from an expected $1: 1$ ratio $(P<0.05)$, with susceptible types predominating (Table 1). Susceptible plants also predominated in line $2 / 2$, but the ratio did not differ statistically from 1:1.

The amount of $F p$ introgression was analysed using GISH in a sample of crown rust-resistant plants, which were also selected for an $L m$ growth habit. The chromosomes of two of the $\mathrm{BC}_{2}$ plants analysed are shown in Figure 2. Plant 3 in line 2/2 (2/2/3) had two introgressed $F p$ segments, one of which was on an $\mathrm{Lm}$ chromosome with an rDNA site that was identified morphologically as being on chromosome 2 (Thomas, 1981). However, this chromosome is now known to correspond to the Poaceae linkage group/chromosome 3 (Armstead et al, 2002; Jones et al, 2002) and this numbering has now been adopted. A second, larger $F p$ segment was on a smaller submedian chromosome, where it had replaced the short arm, centromere and part of the long arm (Figure 2a). Plant 44 in line 2/1 (2/1/44) had one $F p$ segment (Figure $2 \mathrm{~b}$ ). As this chromosome

Table 1 Segregation ratios for crown rust resistance in $\mathrm{BC}_{1}, \mathrm{BC}_{2}$, and $\mathrm{BC}_{3}$ progenies of crosses between Festuca pratensis and Lolium multiflorum ${ }^{2}$

\begin{tabular}{|c|c|c|c|c|c|}
\hline \multirow[t]{2}{*}{$B C$ line } & \multicolumn{3}{|c|}{ Rust reaction type } & \multirow{2}{*}{$\begin{array}{c}\text { Expected } \\
\text { ratio }\end{array}$} & \multirow{2}{*}{$\begin{array}{c}\chi^{2-} \\
\text { values }\end{array}$} \\
\hline & $R$ & $I^{a}$ & $S$ & & \\
\hline \multicolumn{6}{|c|}{$\mathrm{BC}_{1}$} \\
\hline \multicolumn{6}{|c|}{ Derived from resistant $F_{1}$} \\
\hline 1/1 (Bf 993/3) & 6 & 1 & 10 & - & - \\
\hline $1 / 2(\mathrm{Bf} 993 / 3)$ & 10 & 1 & 27 & - & - \\
\hline $1 / 3($ Bf 1204/23) & 13 & 4 & 22 & - & - \\
\hline \multicolumn{6}{|c|}{ Derived from susceptible $F_{1}$} \\
\hline 1/4 (Bf 993/3) & 1 & 1 & 31 & - & - \\
\hline $1 / 5($ Bf $1204 / 20)$ & 0 & 5 & 39 & - & - \\
\hline $1 / 6($ Bf $1204 / 5)$ & 0 & 5 & 22 & - & - \\
\hline $1 / 7(B f 1204 / 5)$ & 0 & 2 & 38 & - & - \\
\hline \multicolumn{6}{|l|}{$\mathrm{BC}_{2}$} \\
\hline $2 / 1$ & 6 & & 47 & $1: 1$ & $31.72^{* * *}$ \\
\hline $2 / 2^{\mathrm{b}}$ & 37 & 2 & 55 & $1: 1$ & $2.72 \mathrm{NS}$ \\
\hline \multicolumn{6}{|l|}{$\mathrm{BC}_{3}$} \\
\hline $3 / 1$ & 31 & & 51 & $1: 1$ & $4.88 *$ \\
\hline $3 / 2$ & 41 & & 48 & $1: 1$ & $0.55 \mathrm{NS}$ \\
\hline
\end{tabular}

IGER accession no./genotype no. of $F$. pratensis parent in parenthesis after $\mathrm{BC}_{1}$ code. $\mathrm{R}=$ resistant, $\mathrm{I}=$ intermediate and $\mathrm{S}=$ susceptible types.

${ }^{a}$ Intermediate types grouped with resistant class for analysis.

${ }^{\mathrm{b}}$ Derived from a cross where the $\mathrm{BC}_{1}$ parent was used as the female parent.

${ }^{*}$ and ${ }^{* *}$ denote significance at $P=0.05$ and 0.001 , respectively. $\mathrm{NS}=$ no significant difference.

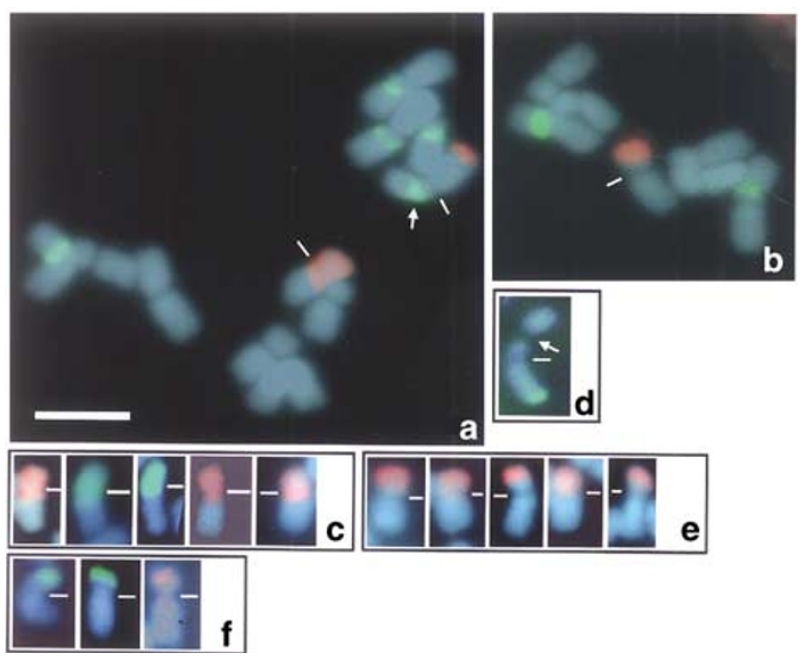

Figure 2 Fluorescent in situ hybridisation of $\mathrm{BC}_{2}$ and $\mathrm{BC}_{3}$ introgression plants. (a, b) GISH with total genomic $F p$ DNA (Cy3 - red) and pTa71 rDNA (fluorescein - green); (a) $\mathrm{BC}_{2}$ genotype 2/2/ 3 part cell with introgressed $\mathrm{Fp}$ segments on the target chromosome (plain line indicating centromere) and chromosome 3 (plain line indicating centromere and arrow indicating NOR); (b) $\mathrm{BC}_{2}$ genotype 2/1/44 part cell with introgressed $F p$ segment on the target chromosome; (c) the target chromosome from five $\mathrm{BC}_{3} \mathrm{R}$ genotypes, line 3/2 with introgressions identified by GISH with $F p$ DNA that was labelled with either Cy3 (red) or fluorescein (green); (d) chromosome 3 from $\mathrm{BC}_{3} \mathrm{~S}$ genotype, line $3 / 2$ with introgression labelled green (plain line indicating centromere and arrow indicating NOR); (e) the target chromosome from five $\mathrm{BC}_{3} \mathrm{R}$ genotypes, line $3 / 1$ with variable size introgressions with $F p$ DNA labelled with $\mathrm{Cy} 3$; (f) the target chromosome from three $\mathrm{BC}_{3} \mathrm{~S}$ genotypes, line $3 / 1$ with $F p$ DNA labelled with either fluorescein or Cy3. The plain line in $(\mathbf{c}, \mathbf{e}, \mathbf{f})$ indicate the centromere position. The bar in (a) represents $10 \mu \mathrm{m}$; all images are the same magnification, but chromosome condensation may vary.

cannot be identified by its morphology, it will be referred to in this paper as the 'target chromosome'. One of the introgressed segments found in $2 / 2 / 3$ was on a chromosome resembling the target chromosome in $2 /$ $1 / 44$ and for now it is assumed to be the same chromosome.

In the $\mathrm{BC}_{3}$ generation lines $3 / 1$ and $3 / 2$, which were derived from plants $2 / 1 / 44$ and $2 / 2 / 3$, respectively (Table 1), gave a very clearcut segregation of R:S plants, with almost all of the resistant plants showing immunity. Both lines were also derived from the same $F p$ parent and $F_{1}$. As with the previous generation, one of the lines $(3 / 1)$ had significantly more susceptible plants than the expected 1:1 ratio.

Five $\mathrm{R}$ and five $\mathrm{S}$ plants were analysed by GISH from each line. In $3 / 2$, all the five $R$ plants had the introgressed segment on the target chromosome and, given the resolution of GISH, the segments appeared not to have been reduced by further recombination (Figure 2c). Two of the R plants also had the Fp segment on chromosome 3 . None of the $S$ plants had the target chromosome introgression, but three of the five plants had the chromosome 3 introgression (Figure 2d). The five $\mathrm{R}$ plants in line $3 / 1$ had an introgressed segment on the chromosome, and this varied in size indicating that further recombination had occurred (compare Figure 2b, e). Three of the five S plants also had an Fp segment on the 
Table 2 Segregation ratios in progenies of pair crosses between crown rust-resistant and -susceptible $\mathrm{BC}_{3}$ plants of crosses between Festuca pratensis and Lolium multiflorum ${ }^{4}$

Cross $\frac{\text { Rust reaction }}{n}$ Expected ratio $\chi^{2}$-values

\begin{tabular}{lllllc}
\hline $\mathrm{S} \times \mathrm{S}$ & & & & & \\
$\quad 3 / 1 / 5 \times 3 / 2 / 25$ & 0 & 0 & 59 & - & - \\
$3 / 2 / 27 \times 3 / 1 / 5$ & 0 & 0 & 66 & - & - \\
& & & & & \\
$\mathrm{R} \times \mathrm{R}$ & 44 & 0 & 15 & $3: 1$ & $0.005 \mathrm{NS}$ \\
$\quad 3 / 1 / 30 \times 3 / 2 / 49$ & 50 & 3 & 21 & & $0.45 \mathrm{NS}$ \\
$3 / 2 / 49 \times 3 / 1 / 3$ & & & & & \\
$\mathrm{R} \times \mathrm{S}$ & & & & & \\
$\quad 3 / 2 / 18(\mathrm{~S}) \times 3 / 1 / 44(\mathrm{R})$ & 72 & 0 & 57 & $1: 1$ & $1.74 \mathrm{NS}$ \\
$3 / 1 / 25(\mathrm{R}) \times 3 / 2 / 36(\mathrm{~S})$ & 62 & 0 & 51 & & $1.07 \mathrm{NS}$
\end{tabular}

$\mathrm{R}=$ resistant, $\mathrm{I}=$ intermediate and $\mathrm{S}=$ susceptible types.

${ }^{a}$ Intermediate types grouped with resistant class for analysis.

$\mathrm{NS}=$ no significant difference.

short arm of the target chromosome, again reduced in size from the original (compare Figure $2 b, f$ ).

Intercrosses were also made between $\mathrm{R}$ and $\mathrm{S}$ plants from the two $\mathrm{BC}_{3}$ lines (Table 2). No $\mathrm{R}$ plants were produced in lines from crosses between $S$ plants. The segregation ratios for $\mathrm{R} \times \mathrm{R}$ and $\mathrm{R} \times \mathrm{S}$ lines did not differ from expected ratios, assuming a single gene or very closely linked genes on the $F p$ segment.

\section{Discussion}

Crown rust resistance has been transferred from the original $\mathrm{Fp}$ parent into $\mathrm{Lm}$. A sample of resistant $\mathrm{BC}_{3}$ plants from two crosses all contained an $\mathrm{Fp}$ chromosome segment, while susceptible plants had either a smaller segment or no segment. The ratios of R:S plants from intercrosses within a sample of $\mathrm{BC}_{3}$ plants demonstrated that they were segregating for a single dominant gene or a group of closely linked genes. This supports the assumption that the introgression in $3 / 1$ and $3 / 2$ is the same segment and therefore the same chromosome. The resistance gene(s) is probably therefore located on this introgressed $F p$ chromosome segment. In 3/2, the second introgressed segment on chromosome 3 segregated independently of rust resistance with two of the five $R$ plants and three of the five $S$ plants having the segment.

The segment on the target chromosome has undergone further recombination in $2 / 1 / 44$, as in the progeny $(3 / 1)$ the segment has been reduced with a range of segment sizes found in both $\mathrm{R}$ and $\mathrm{S}$ genotypes. The physical position of the crown rust resistance locus can be roughly estimated - the $F p$ segments in the $S$ plants appeared similar in size to the smaller of the segments in the $R$ plants (compare Figure 2e, f). The resistance locus must therefore be close to the recombination point and maps physically to the midpoint of the short arm. The resolution of GISH on such contracted mitotic chromosomes means that the gene can only be located to regions of the chromosome arm, that is, in this case, the midpoint. The same Fp segment, though larger, in 2/2/ 3 appears not to have recombined as the segment is either present in the $R$ genotype or absent in the $S$ genotypes in population $3 / 2$ with no variation in size.
Apart from confirming the presence of the resistance locus in the chromosome arm, it does not provide further information on its position.

Disturbed segregation ratios in introgression lines with two marker loci in crosses between $\mathrm{BC}_{1}$ heterozygous plants $(L m / F p)$ and $L m$ were reported by Humphreys and Thorogood (1993). They found that when the $\mathrm{BC}_{1}$ was used as the male parent, there was a reduced transmission of $F p$-derived alleles. In our study, there was a higher proportion of crown rust-susceptible plants in one of the $\mathrm{BC}_{2}$ and $\mathrm{BC}_{3}$ families, indicating a link between deleterious alleles and crown rust resistance. However, the normal segregation ratios in the $\mathrm{BC}_{3}$ intercrosses indicate that the linked deleterious genes have been lost.

Wilkins (1975) found that in the Lm cultivar RvP, crown rust resistance was under the control of a single dominant gene and additional minor genes. Despite selecting susceptible $\mathrm{Lm}$ plants for crossing at each generation, a major concern from the outset was the possibility of accumulating minor genes. By selecting the most resistant plants, that is, giving no disease symptoms (immune), it is possible that this was eliminated since it is unlikely that enough minor genes were accumulated in one generation to give this level of resistance. The intercrosses between susceptible $B_{3}$ plants produced only susceptible progeny, an indication that these at least were not carrying any effective genes for resistance.

\section{Acknowledgements}

This work was mostly funded by the UK Department of Environment, Food and Rural Affairs (formerly Ministry of Agriculture, Fisheries and Food) projects LS1405 and LS3618. We are grateful to members of the IGER Genetic Resources Unit for providing us with the seed of F. pratensis. IGER is an institute of the Biotechnology and Biological Sciences Research Council.

\section{References}

Armstead IP, Turner LB, King IP, Cairns AJ, Humphreys MO (2002). Comparison and integration of genetic maps generated from $\mathrm{F} 2$ and BC1-type mapping populations in perennial ryegrass. Plant Breeding 121: 501-507.

Braverman SW (1967). Disease resistance in cool-season forage, range, and turf grasses. Bot Rev 33: 329-378.

Braverman SW (1986). Disease resistance in cool-season forage, range, and turf grasses II. Bot Rev 52: 1-112.

Clifford BC (1973). The construction and operation of a dewsimulation chamber. New Phytol 72: 619-623.

Dinoor A, Eshed N, Nof E (1988). Puccinia coronata, crown rust of oat and grasses. Adv Plant Pathol 6: 333-344.

Humphreys MW, Pasakinskiene I (1996). Chromosome painting to locate genes for drought resistance transferred from Festuca arundinacea into Lolium multiflorum. Heredity 77: 530534.

Humphreys MW, Thorogood D (1993). Disturbed Mendelian segregation at isozyme marker loci in early backcrosses of Lolium multiflorum $\times$ Festuca pratensis hybrids to L. multiflorum. Euphytica 66: 11-18.

Jauhar PP (1975). Chromosome relationships between Lolium and Festuca (Graminae). Chromosoma 52: 103-121.

Jones ES, Mahoney NL, Hayward MD, Armstead IP, Jones G, Humphreys MO et al (2002). An enhanced molecular marker- 
based genetic map of perennial ryegrass (Lolium perenne L.) reveals comparative relationships with other Poaceae genomes. Genome 45: 282-295.

Kimbeng CA (1999). Genetic basis of crown rust resistance in perennial ryegrass, breeding strategies, and genetic variation among pathogen populations: a review. Austr J Exp Agric 39: 361-378.

King IP, Morgan WG, Armstead IP, Harper JA, Hayward MD, Bollard A et al (1998). Introgression mapping in the grasses. 1. Introgression of Festuca pratensis chromosomes and chromosome segments into Lolium perenne. Heredity 81: 462-467.

Morgan WG (1976). A technique for the production of polyploids in grasses. Euphytica 25: 443-446.

Oertel C, Matzk F (1999). Introgression of crown rust resistance from Festuca spp. into Lolium multiflorum. Plant Breeding 118: 491-496.

Potter LR, Cagas B, Paul VH, Birckenstaedt E (1990). Pathogenicity of some European collections of crown rust (Puccinia coronata Corda) on cultivars of perennial ryegrass. J Phytophathol 130: 119-126.

Reheul D, Baert J, Boller B, Bourdon P, Cagas B, Eickmeyer F et al (2001). Crown Rust, Puccinia coronata Corda: Recent Developments.. In: Paul VH, Dapprich PD (eds) Proceedings of the Third International Conference on Harmful and Beneficial Microorganisms in Grassland, Pastures and Turf. Soest: Germany. pp 17-28.
Roderick HW, Thorogood D, Adomako B (2000). The expression of resistance to crown rust infection in perennial ryegrass (Lolium perenne L.). Plant Breeding 118: 93-95.

Thomas H, Morgan WG, Humphreys MW (1988). The use of a triploid hybrid for introgression in Lolium species. Theor Appl Genet 76: 299-304.

Thomas HM (1981). The Giemsa C-banding karyotypes of six Lolium species. Heredity 46: 263-267.

Thomas HM, Harper JA, Meredith MR, Morgan WG, King IP (1997). Physical mapping of ribosomal DNA sites in Festuca arundinacea and related species by in situ hybridization. Genome 40: 406-410.

Thomas HM, Harper JA, Meredith MR, Morgan WG, Thomas ID, Timms E et al (1996). Comparison of ribosomal DNA sites in Lolium species by fluorescence in situ hybridization. Chromosome Res 4: 486-490.

Thomas HM, Morgan WG, Meredith MR, Humphreys MW, Thomas H, Leggett JM (1994). Identification of parental and recombined chromosomes in hybrid derivatives of Lolium multiflorum $\times$ Festuca pratensis by genomic in situ hybridisation. Theor Appl Genet 88: 909-913.

Wilkins PW (1975). Inheritance of resistance to Puccinia coronata Corda and Rhynchosporium orthosporum Caldwell in Italian ryegrass. Euphytica 24: 191-196.

Wilkins PW, Carr AJH, Lewis EJ (1974). Resistance of Lolium multiflorum/Festuca arundinacea hybrids to some diseases of their parent species. Euphytica 23: 315-320. 